\title{
Conditioning with taste as the CS in conditioned flavor preference learning
}

\author{
ELIZABETH D. CAPALDI, MARTIN J. HUNTER, and SANDRA A. LYN \\ University of Florida, Gainesville, Florida
}

\begin{abstract}
There appear to be unconditioned affective reactions to the four basic tastes: liking for sweet and salt and disliking for sour and bitter. We attempted to modify these reactions by pairing the tastes with calories and with sweeter tastes. Differing sucrose concentrations were ineffective in reversing the preference for salt over citric acid or for saccharin over quinine. We could, however, reverse the preference for salt over citric acid, producing an actual preference for sour over salt, by using sucrose and saccharin as the reinforcers. The initial reactions to tastes could also be modified by reducing the initial difference in affect produced by the tastes through mixing both tastes with sucrose.
\end{abstract}

One of the most commonly used procedures for demonstrating a conditioned aversion is to pair a novel-tasting substance-most often saccharin-with poison. Subsequently, rats avoid saccharin. Indeed, aversion learning is often referred to as taste aversion learning. In this paradigm, tastes - such as saccharin from the example abovehave been viewed as functioning as the unconditioned stimuli (USs; Garcia, 1989) as well as the conditioned stimulus (CS; Brackbill, Rosenbush, \& Brookshire, 1971; Nowlis, Frank, \& Pfaffmann, 1980). Garcia (1989) has argued that taste is always a US because its properties are motivationally significant. Garcia suggests that conditioned flavor aversions be divided into two components: the US (e.g., tastes), which denotes stimulation of food in the mouth, and FB (e.g., nausea), which denotes feedback from food in the gut. As the FB, nausea decreases the incentive value of the taste US. In other words, saccharin followed by nausea causes a negative affective reaction.

Brackbill et al. (1971), however, suggest that tastes function as the CS in conditioned taste aversions, and illness or nausea function as the US. They found that the effectiveness of a taste as a CS depended on its taste quality. They used salt, saccharin, and citric acid as the CSs and sickness as the US; they found that an aversion could be established to salt or saccharin but not to citric acid. Brackbill et al. suggest that this occurs because citric acid is a nonpreferred substance because of its sour taste quality, whereas there was no such problem with salt and saccharin because they are preferred substances (salt and sweet taste).

Nowlis et al. (1980), however, found that aversion learning did not depend on the taste quality of the CS. Using rats and hamsters, they measured conditioned aversion to various taste CSs. After training, each subject was tested

This research was supported in part by Grant IBN-9419986 from the National Science Foundation to the first author. Requests for reprints should be sent to E. D. Capaldi, Department of Psychology, University of Florida, Gainesville, FL 3261 1-2065 (e-mail: capaldi@nersp. nerdc.ufl.edu). with the four basic tastes: $\mathrm{NaCl}$ (salt), sucrose (sweet), $\mathrm{HCl}$ (sour), and quinine hydrochloride (bitter). During testing, animals showed an aversion only to the taste quality that had been paired with sickness in training; conditioning was equally effective to each of the basic tastes. From this experiment, it appears that tastes can be effective CSs in conditioned aversion learning, regardless of taste quality.

In conditioned preference learning, tastes are usually used as a US, not as the CS. Fanselow and Birk (1982), for example, showed that rats prefer a flavor extract that has been paired with saccharin to one paired with quinine. There appears to be an inherent liking or disliking for each of the four basic tastes-salt, sour, sweet, and bitter-such that they can serve effectively as USs. There is an inherent liking for sweet and salt and an inherent disliking for sour and bitter (Bartoshuk, 1991). Odorous cues are most often used as the CSs, in conditioned preference experiments - flavor extracts and Kool Aid flavors being the most common (see, e.g., Elizalde \& Sclafani, 1990; Fedorchak \& Bolles, 1987).

We are interested here in whether the initial affective reactions to tastes can be overcome in conditioned preference learning. Conditioned preferences may not be strong enough to overcome the initial unlearned preferences for salt and sweet over sour and bitter. Many researchers believe that aversion learning is stronger than preference conditioning (see, e.g., Rozin, Gruss, \& Berk, 1979). Thus, aversion conditioning may be strong enough to reverse initial preferences between tastes, whereas preference conditioning may fail to do so. Conditioned preferences for tastes as the CS have been shown using the effects of drugs as the US. Zellner, Berridge, Grill, and Ternes (1985), using morphine as the US, found that rats acquired a liking for the bitter flavor of morphine through association with the positive postingestional consequences of the morphine, which finding suggests that tastes can act as CSs in preference learning. They found that morphine increased palatability. Similarly, Touzani, Akarid, and Velley (1991) and Doyle, Berridge, 
and Gosnell (1993) showed that the effects of morphine increased taste palatability. In the case of decreasing preference for tastes, Lynch and Libby (1983) used naloxone to decrease the palatability of saccharin. However, no one has determined whether the preference for salt over sour or sweet over bitter can actually be reversed by preference conditioning. This is what we attempt to do here. We are interested in whether pairing a less preferred taste (sour, bitter) with a high-calorie US while simultaneously pairing a more preferred taste (salt, sweet) with a lower calorie US would reverse the normal preferences.

Sucrose concentration, which has been used successfully in previous studies (see, e.g., Fedorchak \& Bolles, 1987), was used as the reinforcer. The purpose of Experiment 1 was to determine whether sucrose concentration can reverse the initial unconditioned preferences between tastes.

\section{EXPERIMENT 1}

In Experiment 1, each of the four basic tastes--salt (salt), citric acid (sour), saccharin (sweet), and quinine (bitter) - was used as a cue that was subject to preference conditioning. Each rat received a liked taste paired with one reinforcer and a disliked taste paired with a different reinforcer. Half of the rats were trained with salt and citric acid, half with saccharin and quinine. The objective was to see whether we could condition the rats to prefer either taste, regardless of its inherent value. Concentrations of sucrose $(20 \%$ and $2 \%$ ) were used as the reinforcers. For comparison with the conditioning of taste, an odor group was included in these experiments as well. We used flavor extracts (almond and vanilla) as odor cues, which extracts we had used before as targets of conditioned preferences (Capaldi \& Hunter, 1994). The extracts may have tastes, but Rusiniak, Hankins, Garcia, and Brett (1979) have shown that, in aversion conditioning, rats react to almond extract primarily on the basis of its smell. The concentrations of salt $(0.2 \%)$ and citric acid $(0.031 \%)$ were those used by Holder (1991).

\section{Method}

Subjects. The subjects were 30 naive male Sprague-Dawley rats from Harlan Co., Indianapolis. They were 70 days old (weight $275-300 \mathrm{~g}$ ) upon arrival and 73 days old at the start of the experiment.

Materials and Apparatus. Solutions in all experiments (weight/volume) were presented in $50-\mathrm{ml}$ Nalgene centrifuge tubes with rubber stoppers and metal spouts. Tastes were $0.2 \%$ $\mathrm{NaCl}$ and $0.031 \%$ citric ac1d, which were purchased from Fisher Screntific, Fair Lawn, NJ, and $0.00396 \%$ quinine hydrochloride hydrate and $0.012 \%$ saccharın, which were purchased from Sigma Chemical, St. Louis. Odors were $2 \%$ almond extract and $2 \%$ vanilla extract, both McCormick's brand. All stimuli were presented in $40 \mathrm{ml}$ of distilled water, which also contained either $20 \%$ or $2 \%$ sucrose, purchased from Publix Supermarket. The rats were trained and tested in their home cages. A 12:12-h light:dark cycle was always in effect, with lights on at 6 a.m. Subjects showed no reluctance to drink the solutions.

Procedure. Ad-lib water was present throughout the exper1ment in clear plastic bottles mounted to the right of the food hop- per on each cage front. On Day 1, all food was removed from the cages. On Days 2-11, rats were fed $14 \mathrm{~g}$ of lab chow (Lab Diet 5001; PMI Feeds, Inc., St. Louis) each day at 11:30 a.m.; during training (which was at 8:15 a.m.), they were fed at 1:00 p.m., with rations reduced to compensate for calories consumed in the sucrose. Each gram of lab chow contained 3.2 calories, for a total of 44.8 calories per day per rat. For every $5 \mathrm{ml}$ of $20 \%$ sucrose (equal to 3.2 calories) consumed, $1 \mathrm{~g}$ of food was removed so that the total calories consumed each day would remain at 44.8 calories.

There were 12 days of training, beginning on Day 12. The 30 rats were divided randomly into three groups of 10 subjects each. Group T-SaltC was trained with the tastes salt and citric acid Group T-SaccQ was trained with the tastes saccharin and quinine. Both groups received one taste mixed with $20 \%$ sucrose and the other with 2\% sucrose. Group Extract was trained with the extracts (almond and vanilla), one extract mixed with $20 \%$ sucrose and the other with $2 \%$ sucrose. All stimuli were counterbalanced. For example, half of Group T-SaltC received salt mixed with $20 \%$ sucrose and citric acid mixed with $2 \%$ sucrose; the remaining half received the reverse pairings. The other groups were divided in the same manner. The solutions were presented on an ABBA schedule over days. All solutions were presented in $40-\mathrm{ml}$ portions for 10 min each day.

There were 4 days of testing immediately following training. All rats received a two-bottle test $(40 \mathrm{ml}$, side by side) for $4 \mathrm{~h}$ between the two cues they received in training (Group T-SaltC received salt vs. citric acid in water, Group T-SaccQ received saccharin vs. quinine in water, and Group Extract received almond vs. vanilla in water). All water bottles were removed during the test. The tubes were placed on the cages (either on the left or on the right) on an ABBA schedule. For all of the rats during testing, one tube was put into each cage and moved briefly so that each rat would approach and contact the tube; the same was then done for the other tube to ensure that the rat contacted both solutions.

\section{Results}

Training. All of the groups drank more of the $20 \%$ sucrose solution than they did of the $2 \%$ sucrose solution; this difference grew larger over days. Group T-SaccQ drank less than the other groups.

An analysis of variance (ANOVA) included groups and counterbalancing (evaluating any effects of the particular taste or extract that was paired with $20 \%$ or $2 \%$ sucrose) as the between factors and days and $20 \%$ sucrose solution versus $2 \%$ sucrose solution as the within factors. All groups increased consumption over days $[F(5,120)=$ $182.57, p<.001]$ and drank more of the $20 \%$ sucrose solution than of the $2 \%$ sucrose solution $[F(1,24)=288.44$, $p<.0001]$. The difference attributable to sucrose solution grew larger over days $[F(5,120)=30.89, p<.0001]$. Sucrose concentration interacted with counterbalancing $[F(1,24)=39.84, p<.001]$; rats drank less when the sucrose solution contained citric acid than they did when it contained salt and less when it contained quinine than they did when it contained saccharin. The mean millimeters consumed of the various taste cues during training is shown in Table 1. The difference in consumption due to taste was largest for saccharin versus quinine, producing a significant group $\times$ solution $\times$ counterbalancing interaction $[F(2,24)=12.37, p<.001]$. A comparison of pairs of groups with respect to the size of the difference in counterbalancing showed that the difference in consumption between the taste cues in Group T- 
Table 1

Mean Amount Consumed (in Milliliters) of Each Taste Cue in Training in Experiment 1

\begin{tabular}{|c|c|c|c|c|}
\hline \multirow[b]{2}{*}{ Group } & \multicolumn{2}{|c|}{ Mixed With $20 \%$ Sucrose } & \multicolumn{2}{|c|}{ Mixed With $2 \%$ Sucrose } \\
\hline & Cue & Amt. & Cue & Amt. \\
\hline \multirow[t]{2}{*}{ T-SaltC } & salt & 14.43 & citric & 6.50 \\
\hline & citric & 11.80 & salt & 8.60 \\
\hline \multirow[t]{2}{*}{$\mathrm{T}-\mathrm{Sacc} \mathrm{Q}$} & saccharin & 11.73 & quinine & 2.10 \\
\hline & quinine & 9.90 & saccharin & 7.77 \\
\hline \multirow[t]{2}{*}{ Extract } & almond & 13.20 & vanilla & 8.50 \\
\hline & vanilla & 12.50 & almond & 7.63 \\
\hline
\end{tabular}

Note-In each row, the taste cues are given in the order of their presentation. Half the rats in each group received one presentation order; half received the other.

SaccQ was significantly larger than that of Group TSaltC $[F(1,16)=61.40, p<.001]$ and that of Group Extract $[F(1,16)=22.06, p<.001]$. The difference for Group Extract was significantly smaller than that for Group T-SaltC $[F(1,16)=8.56, p<.01]$.

Groups also differed in their overall consumption $[F(2,24)=11.94, p<.001]$, with Group T-SaccQ drinking less than the other groups. Newman-Keuls tests $(p<.05)$ showed that both Group Extract and Group T-SaltC consumed significantly more than Group T-SaccQ. NewmanKeuls tests also revealed that all of the groups consumed significantly more of the cue paired with $20 \%$ sucrose than of the cue paired with $2 \%$ sucrose.

Testing. Figure 1 shows the amount consumed by each group in test. Group Extract drank more of the extract that had been paired with $20 \%$ sucrose than of the

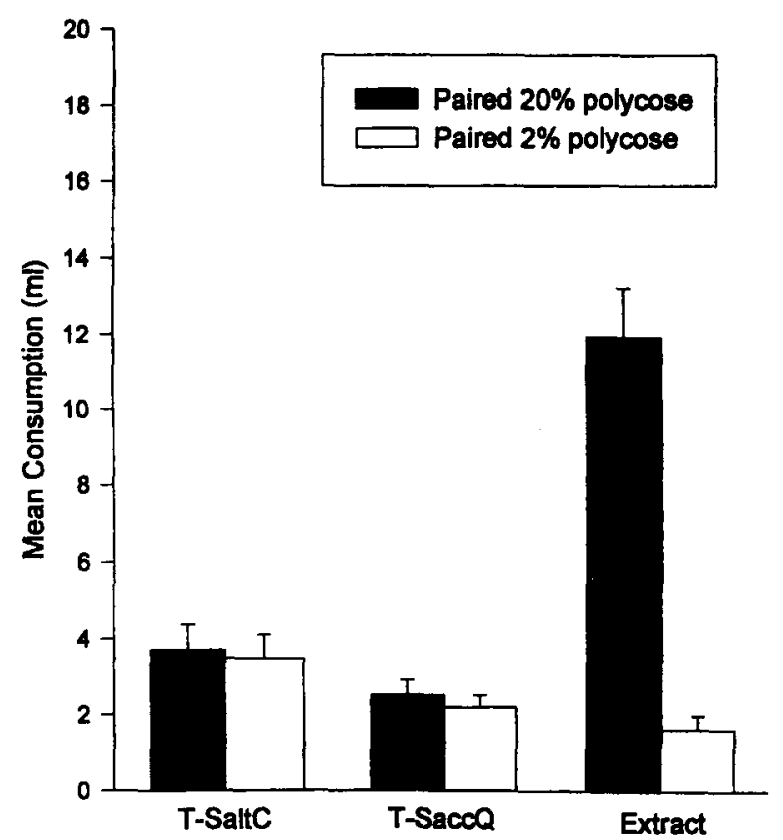

Figure 1. Mean milliliters consumed in test of the tastes (Group T-SaltC and T-SaceQ) or extracts (Group Extract) that had been paired with $20 \%$ sucrose or $2 \%$ sucrose in training. In the test, tastes and extracts were given in water. Vertical lines represent standard error of the mean. one that had been paired with $2 \%$ sucrose; however, there was no difference for either taste group.

An ANOVA included groups and counterbalancing as the between factors and days and flavor (taste or extract) in test as the within factors. The term preference is used here to refer to greater consumption of one solution than of another in a two-bottle test. Thus, we do not use the term for training data, but only for test. In Experiment 1, the preference that was measured was that for the taste or extract that had been paired with $20 \%$ sucrose over that for the taste or extract paired with $2 \%$ sucrose. The analysis showed that there was a significant preference $[F(1,24)=23.14, p<.001]$, which varied by group [preference $\times$ group; $F(2,24)=19.77, p<.05]$. A comparison of pairs of groups with respect to the size of their preference showed that the preference for Group Extract was significantly larger than that of either taste group [group $\times$ preference for Group Extract vs. Group TSaltC, $F(1,16)=29.95, p<.001$, and for Group Extract vs. Group T-SaccQ, $F(1,16)=29.36, p<.001]$. The preference $X$ group interaction was not significant when comparing the two taste groups $(F<1)$. Newman-Keuls tests $(p<.05)$ revealed that Group Extract drank significantly more of the extract paired with $20 \%$ sucrose than of the extract paired with $2 \%$ sucrose, whereas this difference was not significant for either taste group.

In the analysis, the preference $\times$ counterbalancing interaction was significant $[F(1,24)=5.27, p<.05]$; in the test, groups preferred salt to citric acid, saccharin to quinine, and almond to vanilla, regardless of the sucrose solution with which these taste or extract cues had been paired. There was also a significant group $\times$ preference $\times$ counterbalancing interaction $[F(2,24)=10.31, p<$ $.001]$. As shown in Table 2, Group T-SaltC preferred salt over citric acid, and Group T-SaccQ preferred saccharin over quinine, whether they were paired with $20 \%$ sucrose or with $2 \%$ sucrose. A comparison of Group Extract with Group T-SaltC revealed that there was a significant difference in counterbalancing between these groups $[F(1,16)=$ $19.05, p<.01]$, as well as between Group Extract and Group T-SaccQ $[F(1,16)=19.76, p<.01]$. There was also a significant difference between the two taste groups $[F(1,16)=9.16, p<.05]$. Group Extract preferred the cue paired with $20 \%$ sucrose to that paired with $2 \%$ sucrose, whether it was almond or vanilla, although the preference was larger if almond was paired with $20 \%$ sucrose.

\section{Discussion}

Experiment 1 demonstrated a conditioned preference for extracts when concentrations of sucrose were used as a reinforcer, whereas no preference was formed when this reinforcer was used for tastes. Thus it appears that the calories contained in the sucrose were not enough to overcome the initial reactions to the tastes. The problem was not that the taste stimuli were too weak to be discriminated from one another. The animals in Experiment 1 drank less quinine than saccharin and less citric acid than salt in training, and they preferred salt to citric acid and saccharin to quinine in test, indicating that they 
Table 2

Mean Amount Consumed (in Milliliters) of Each Taste Cue in Test in Experiment 1

\begin{tabular}{|c|c|c|c|c|}
\hline \multirow[b]{2}{*}{ Group } & \multicolumn{2}{|c|}{ Paired With $20 \%$ Sucrose } & \multicolumn{2}{|c|}{ Paired With $2 \%$ Sucrose } \\
\hline & Cue & Amt. & Cue & Amt \\
\hline \multirow[t]{2}{*}{ T-SaitC } & salt & 6.00 & citric & 3.05 \\
\hline & citric & 1.40 & salt & 3.90 \\
\hline \multirow[t]{2}{*}{ T-SaccQ } & saccharin & 3.75 & quinine & .55 \\
\hline & quinine & 1.30 & saccharin & 3.85 \\
\hline \multirow[t]{2}{*}{ Extract } & almond & 17.75 & vanilla & 2.05 \\
\hline & vanilla & 6.20 & almond & 1.20 \\
\hline
\end{tabular}

Note-In each row, the taste cues are given in the order of their presentation. Half the rats in each group received one presentation order; half received the other.

could discriminate these taste cues. We cannot tell at this point whether the discrimination of the taste cues is due to the taste qualities actually being tasted or to the intensity of the taste cues being sensed (e.g., citric acid having a stronger taste compared with salt). In Experiment 2, we increased the intensity of the tastes to see if that would lead to successful preference conditioning to tastes.

A more likely reason why we failed to obtain conditioning in Experiment 1 is that the difference in reinforcement produced by $20 \%$ sucrose as opposed to $2 \%$ sucrose was not large enough to counteract the initial preference differences between the tastes. Holder (1991) and Capaldi and Hunter (1994) were successful in finding conditioned taste preferences using sucrose and saccharin as the reinforcers rather than concentration of sucrose. Sucrose and saccharin differ in both taste and calories (sucrose has calories, saccharin has none; sucrose is sweet tasting, saccharin is both sweet and bitter tasting). In Experiment 2, we used the same high concentration of sucrose as that used in Experiment 1 for the larger reinforcer, but we used saccharin rather than the low concentration of sucrose for the small reinforcer. We sought to determine whether increasing the difference between the reinforcers in this way would successfully counteract the initial taste preferences and thus produce conditioned taste preferences.

\section{EXPERIMENT 2}

The procedures of Experiment 2 were the same as those of Experiment 1, except that a low concentration of saccharin $(0.012 \%)$ was used in the place of $2 \%$ sucrose.
We used salt and citric acid as the taste stimuli. Group Taste received the same intensities of these cues as it did in Experiment 1; for Group Double-Taste, the concentrations of salt and citric acid were doubled. Group Extract received the same treatment as in Experiment 1.

\section{Method}

Subjects. The subjects were 30 naive rats of the same description as in the previous experiment. There were 12 subjects in Group Extract and Group Taste and 8 subjects in Group Double-Taste.

Materials. Solutions were identical to those of Experiment 1 , except that $2 \%$ sucrose was replaced with $0.012 \%$ saccharin. Group T-SaltC was now called Group Taste and received the same cues (salt and citric acid) as in Experiment 1. For Group DoubleTaste, the taste stimuli from Group Taste were doubled; so, the concentration of salt was $0.4 \%$ and the concentration of citric acid was $0.062 \%$. Group Extract was not changed.

Procedure. The procedure was identical to that of Experiment 1 , with the noted exceptions.

\section{Results}

Training. All of the groups drank more of the sucrose solution than the saccharin solution; this difference grew larger over days.

An ANOVA included groups and counterbalancing as the between factors and days and sucrose solution versus saccharin solution as the within factors. Consumption increased over days $[F(5,130)=166.07, p<.001]$, all groups drank more sucrose than saccharin $[F(1,26)=$ $1,188.54, p<.001]$, and this difference grew larger over days $[F(5,130)=97.89, p<.001]$. The solution $\times$ group $\times$ counterbalancing interaction was significant $[F(2,26)=6.01, p<.01]$. The effects of counterbalancing are shown in Table 3. A comparison of pairs of groups with respect to size of difference in counterbalancing revealed that there was a significant difference between Group Taste and Group Extract [Group Taste $\times$ Group Extract $\times$ counterbalancing, $F(1,16)=11.92, p<.01]$. There was no difference between the two taste groups $[F(1,16)=1.65, p>.05]$ or between Group DoubleTaste and Group Extract $[F(1,16)=3.25, p>.05]$.

Testing. In test, as Figure 2 shows, all groups drank more of the taste or extract that had been paired with sucrose than they did of the taste or extract that had been paired with saccharin, with the size of the difference greatest in Group Extract, next greatest in Group DoubleTaste, and smallest in Group Taste.

Table 3

Mean Amount Consumed (in Milliliters)

of Each Taste Cue in Training in Experiment 2

\begin{tabular}{|c|c|c|c|c|}
\hline \multirow[b]{2}{*}{ Group } & \multicolumn{2}{|c|}{ Mixed With 20\% Sucrose } & \multicolumn{2}{|c|}{ Mixed With .012\% Saccharin } \\
\hline & Cue & Amt. & Cue & Amt. \\
\hline \multirow[t]{2}{*}{ Taste } & salt & 12.17 & citric & 1.81 \\
\hline & citric & 9.33 & salt & 1.42 \\
\hline \multirow[t]{2}{*}{ Double-taste } & salt & 11.29 & citric & 1.21 \\
\hline & citric & 11.46 & salt & 1.96 \\
\hline \multirow[t]{2}{*}{ Extract } & almond & 11.44 & vanilla & 1.86 \\
\hline & vanilla & 13.39 & almond & 1.78 \\
\hline
\end{tabular}

Note-In each row, the taste cues are given in the order of their presentation. Half the rats in each group received one presentation order; half received the other. 


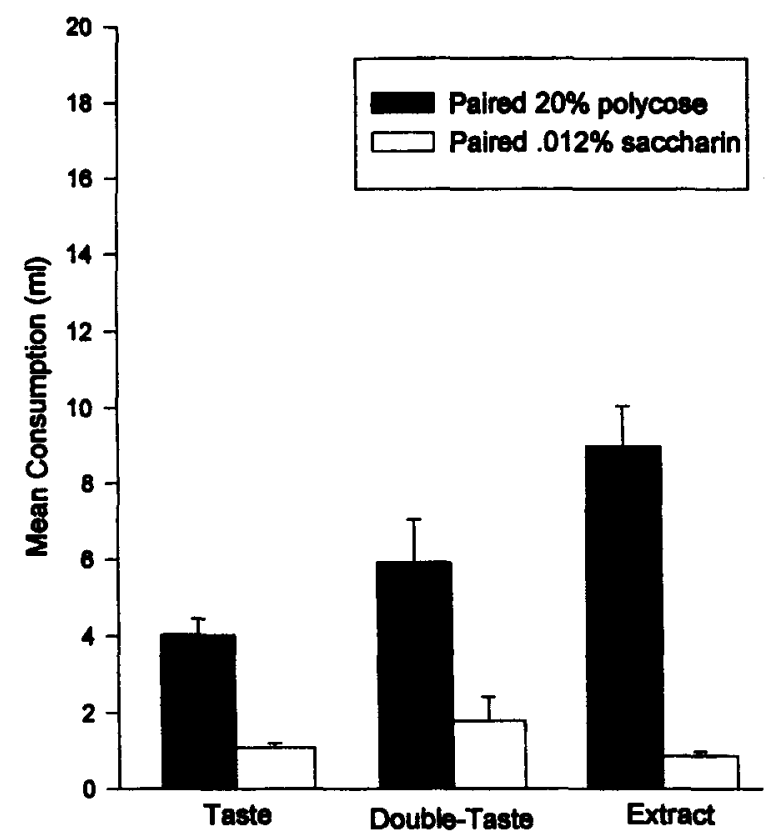

Figure 2. Mean milliliters consumed in test of the tastes (Group Taste and Double-Taste) or extracts (Group Extract) that had been paired with $20 \%$ sucrose or $.012 \%$ saccharin in training. In the test, tastes and extracts were given in water. Vertical lines represent standard error of the mean.

An ANOVA included the same factors as in the previous experiment. The overall preference was significant $[F(1,26)=95.71, p<.001]$, and the size of this preference did vary by group $[F(2,26)=10.49, p<.001]$. A comparison pairs of groups in size of preference, as in the previous experiment, showed that Group Extract showed a larger preference than did either taste group [group $X$ preference comparing Group Extract to Group Taste, $F(1,20)=19.54, p<.01 ;$ group $\times$ preference comparing Group Extract to Group Double-Taste, $F(1,16)=9.30$, $p<.01]$. The two taste groups did not differ in size of preference $(F<1)$. However, it is most important that Newman-Keuls tests $(p<.05)$ revealed that all three groups showed a significant preference-that is, they drank significantly more of the cue that had been paired with sucrose than they did of the cue that had been paired with saccharin.
The group $\times$ preference $\times$ counterbalancing interaction was also significant $[F(2,26)=6.41, p<.01]$. Table 4 shows the effects of counterbalancing. In a pairwise comparison, Group Extract differed from Group Taste [Group Extract $\times$ Group Taste $\times$ preference $\times$ counterbalancing, $F(1,20)=11.02, p<.01]$ but did not differ from Group Double-Taste $(F<1)$. The two taste groups also differed $[F(1,20)=7.20, p<.05]$. Group Extract consumed more almond than vanilla, and Group DoubleTaste consumed more salt than citric acid.

\section{Discussion}

The results of Experiment 2 show that, if the reinforcer is large enough, initial taste preferences can be reversed by conditioning. In Experiment 2, in the test, Group Taste preferred citric acid to salt after citric acid had been paired with $20 \%$ sucrose and salt had been paired with $0.012 \%$ saccharin. Thus, we reversed the initial preference for salt over citric acid in Group Taste. For Group Double-Taste, we eliminated the preference for salt over citric acid by pairing salt with sucrose and citric acid with saccharin, but we did not reverse it in test. Group Double-Taste showed no preference between $0.4 \%$ salt and $0.062 \%$ citric acid. As in Experiment 1 , in Experiment 2 Group Extract showed a preference for the extract paired with the larger reinforcer, whether that extract was almond or vanilla.

The sucrose and saccharin used in Experiment 2 differed more in calories than those used in Experiment 1 (20\% sucrose vs. $2 \%$ sucrose in Experiment 1, 20\% sucrose vs. $0.012 \%$ saccharin in Experiment 2). Also, saccharin differs in taste from sucrose, having a bitter as well as a sweet taste component (Morrison \& Jessup, 1977). This larger difference between the reinforcers may explain why we were successful in Experiment 2 in overcoming the initial preference between the tastes, while concentration of sucrose alone was insufficient in Experiment 1.

\section{EXPERIMENT 3}

In Experiment 1, we failed to find a conditioned preference using tastes as the CS when the reinforcer was $20 \%$ sucrose as opposed to $2 \%$ sucrose. In Experiment 1, we trained tastes together that were opposite in affective value. If the initial affective reaction to the tastes makes it difficult to condition preferences, minimizing the af-

Table 4

Mean Amount Consumed (in Milliliters) of Each Taste Cue in Test in Experiment 2

\begin{tabular}{lllllr}
\hline \multirow{2}{*}{ Group } & \multicolumn{2}{c}{ Paired With $20 \%$ Sucrose } & & \multicolumn{2}{c}{ Paired With .012\% Saccharin } \\
\cline { 2 - 3 } \cline { 5 - 6 } Taste & Cue & Amt. & & Cue & Amt. \\
& salt & 3.46 & & citric & 1.13 \\
Double-taste & citric & 4.58 & & salt & 1.04 \\
& salt & 8.88 & & citric & .63 \\
Extract & citric & 2.84 & & salt & 2.94 \\
& almond & 13.58 & & vanilla & .96 \\
& vanilla & 4.38 & & almond & .75 \\
\hline
\end{tabular}

Note--In each row, the taste cues are given in the order of their presentation. Half the rats in each group received one presentation order; half received the other. 
fective reaction to the taste cues should allow preferences to be conditioned to taste stimuli. The purpose of Experiment 3 was to test this hypothesis.

In Experiment 3, we attempted to minimize the difference between the taste cues in two ways. First, we used tastes that were closer in affective value. In Experiments 1 and 2, salt was pitted against citric acid (salt being preferred) and saccharin was pitted against quinine (saccharin being preferred). In Experiment 3, salt and saccharin were trained because of their similar taste qualities (pleasant quality). Second, to further reduce affective differences, we mixed $2 \%$ sucrose with all of the tastes and used polycose $(20 \%$ and $2 \%)$ rather than sucrose as the reinforcer. The reinforcer was delivered at a delay, either $5 \mathrm{~min}$ or $4 \mathrm{~h}$ after the cues were consumed.

In an unpublished experiment, the taste cues were mixed with $20 \%$ sucrose, as in Experiment 2, and then followed by the polycose reinforcer. However, a conditioned preference for taste was not found. One of the problems in this experiment was that the experimental groups did not drink as much of the reinforcer as did the control groups, probably because of the calories contained in the $20 \%$ sucrose. The reinforcers were presented 5 min after the presentation of the tastes for the experimental groups, whereas the control groups received the reinforcer $4 \mathrm{~h}$ later. Apparently the consumption of the $20 \%$ sucrose reduced the animals' motivation to consume the polycose reinforcer. As a result, we decided to decrease the concentration of the sucrose to $2 \%$.

\section{Method}

Subjects. The subjects were 24 naive rats of the same description as in the previous experiments. There were 12 subjects in both the Taste Group and the Control Group.

Materials. Only taste cues-salt and saccharin-were used; their respective concentrations remained the same as in the previous experiments. Each taste cue was mixed with $2 \%$ sucrose. The reinforcers were $20 \%$ and $2 \%$ polycose, purchased from Ross Laboratories, Columbus, $\mathrm{OH}$. Both the cues and reinforcers were presented in $40-\mathrm{ml}$ portions. Test solutions were the taste cues mixed with $2 \%$ sucrose.

Procedure. The training procedure was the same as in the previous experiments, with the following changes. As previously mentioned, the reinforcers were presented after a delay rather than mixed in with the cues. The delay was $5 \mathrm{~min}$ for the taste group and $4 \mathrm{~h}$ for the control group. The reinforcers were $20 \%$ and $2 \%$ polycose, rather than $20 \%$ and $2 \%$ sucrose. Rations were reduced in order to compensate for calories consumed in the $20 \%$ polycose solution (every $4 \mathrm{ml}$ of polycose consumed equaled $1 \mathrm{~g}$ of $\mathrm{chow}$ ).
Testing was the same as in the previous experiments, except that the taste cues were presented in $2 \%$ sucrose, as they were during training.

\section{Results}

Training. In training, the taste group consumed more of the cue paired with $20 \%$ polycose than of the cue paired with $2 \%$ polycose; this difference increased over days. The control group did not consume the two solutions differentially.

An ANOVA of consumption of the taste cues included groups and counterbalancing as the between factors and days and the solution paired with $20 \%$ polycose solution as opposed to the solution paired with $2 \%$ polycose as the within factors. The difference in amount consumed between the taste cue paired with $20 \%$ polycose and the taste cue paired with $2 \%$ polycose was significant $[F(1,20)=24.71, p<.001]$, as was the days $\times$ solution interaction $[F(9,180)=85.02, p<.0001]$. This difference varied by group $[F(1,20)=20.66, p<.001]$. Newman-Keuls tests $(p<.05)$ showed that Group Taste consumed significantly more of the cue that was paired with $20 \%$ polycose than of the one that was paired with $2 \%$ polycose; however, the control group did consume the cues differentially. The group $\times$ counterbalancing interaction was significant $[F(1,20)=21.90, p<.001]$ because there was a larger difference in the consumption of the salt cue than of the saccharin cue, as is shown in Table 5 . However, the group $\times$ preference $\times$ counterbalancing interaction was not significant $(p>.1)$. There was no difference in consumption between the $20 \%$ polycose solution and the $2 \%$ polycose solution $[F(1,20)=3.93, p>.06]$, nor did this vary by group $[F(1,20)=2.41, p>.1]$.

Testing. Figure 3 shows the mean amount consumed of the tastes during the test. Preference was significant $[F(1,20)=36.39, p<.0001]$ and varied by group $[F(1,20)=24.70, p<.001]$ because Group Control did not show a preference, whereas Group Taste did. NewmanKeuls tests $(p<.05)$ showed that Group Taste consumed significantly more of the $20 \%$-polycose-paired cue than of the $2 \%$-polycose-paired cue; there was no difference for the control group. The preference $\times$ counterbalancing interaction was not significant $(F<1)$, nor was the group $\times$ preference $\times$ counterbalancing interaction $[F(1,20)=1.23, p>.20]$. Table 6 shows the effects of the different taste cues in Experiment 3 's test.

Table 5

Mean Amount Consumed (in Milliliters) of Each Taste Cue and Reinforcer in Training in Experiment 3

\begin{tabular}{|c|c|c|c|c|c|c|}
\hline \multirow[b]{2}{*}{ Group } & \multicolumn{3}{|c|}{ Paired With $20 \%$ Polycose } & \multicolumn{3}{|c|}{ Paired With $2 \%$ Polycose } \\
\hline & Cue & Cue Amt. & $\begin{array}{c}\text { Reinforcer } \\
\text { Amt. }\end{array}$ & Cue & Cue Amt. & $\begin{array}{c}\text { Reinforcer } \\
\text { Amt. }\end{array}$ \\
\hline \multirow[t]{2}{*}{ Taste } & salt-sucrose & 10.17 & 14.95 & saccharin-sucrose & 4.32 & 13.77 \\
\hline & saccharin-sucrose & 8.50 & 15.62 & salt-sucrose & 7.28 & 13.23 \\
\hline \multirow[t]{2}{*}{ Control } & salt-sucrose & 9.65 & 15.88 & saccharin-sucrose & 8.33 & 15.25 \\
\hline & saccharin-sucrose & 8.73 & 15.00 & salt-sucrose & 9.73 & 15.20 \\
\hline
\end{tabular}

Note-In each row, the taste cues are given in the order of their presentation. Half the rats in each group received one presentation order; half received the other. 


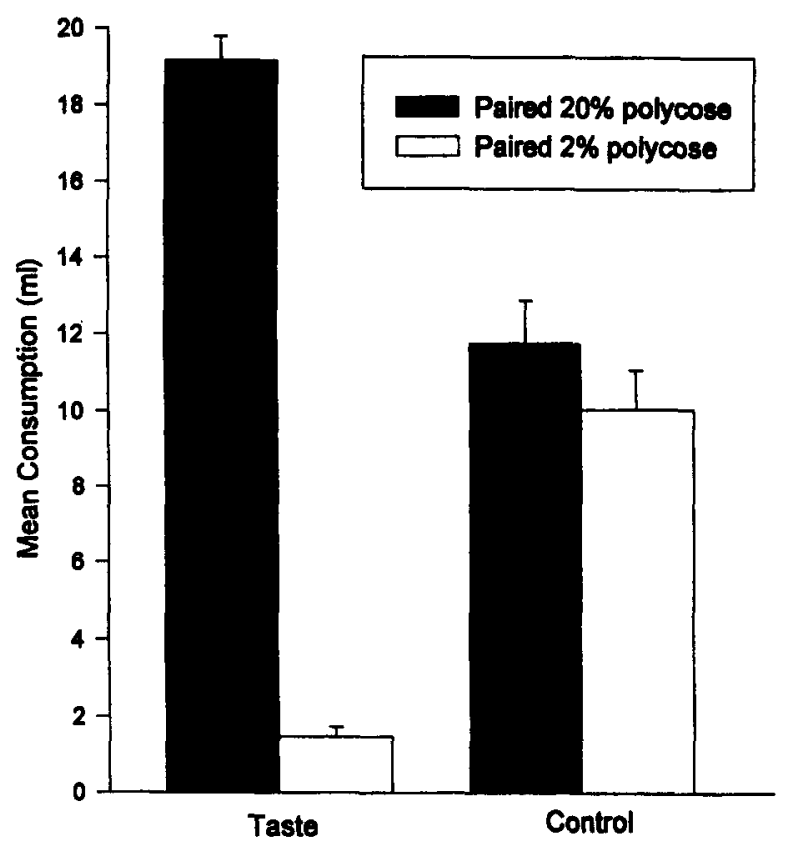

Figure 3. Mean milliliters consumed in test of the tastes (salt and saccharin) that had been paired with $20 \%$ polycose or $2 \%$ polycose in training. In the test, the tastes were presented in $\mathbf{2 \%}$ sucrose. Vertical lines represent standard error of the mean.

\section{Discussion}

The results of Experiment 3 show that a conditioned preference can be obtained with taste cues by using a reinforcer that varied in concentration (polycose). In Experiment 3 , we minimized the effects of the initial affective reaction to the tastes by using two positively valued tastes (salt and saccharin) and by mixing them with $2 \%$ sucrose. The $2 \%$ sucrose was effective in reducing the affective difference between the tastes. There was no effect of counterbalancing in Experiment 3; rats consumed the same amount of the salt and saccharin cues. Now that we have determined that two positively valued tastes can be conditioned, what about two negatively valued tastes?

\section{EXPERIMENT 4}

In Experiment 4, we were interested in determining whether tastes that are inherently unpleasant- that is, citric acid and quinine-could be conditioned by using the same procedures that were effective with salt and saccharin, which are inherently pleasant tastes. However, the procedures had to be changed, because rats would not drink the quinine solutions. In an unpublished experiment, rather than mixing the taste cues with $2 \%$ sucrose, we mixed them with $3.42 \%$ sucrose in order to overcome this problem. However, during training, the consumption of quinine was still very low. So, in Experiment 4 , the rats were preexposed to the taste cues mixed with $3.42 \%$ sucrose for 14 days and then began training with the reinforcers. After 4 days of preexposure without the reinforcers, the rats still were not drinking. We then increased the sucrose concentration to $8 \%$.

\section{Method}

Subjects. The subjects were 24 naive rats of the same description as in the previous experiments. There were 6 subjects in each of the following groups: Group Pre-Exp-Taste, Group Pre-Exp-Ctl, Group Taste, and Group Control.

Materials. In training, the concentrations of the taste cues (citric acid and quinine) were the same as in Experiment 1. For the first 4 days of preexposure, the tastes were mixed in $3.42 \%$ sucrose (weight/volume). As noted earlier, because subjects did not drink appreciable amounts of the quinine solution, the sucrose concentration was increased to $8 \%$. For the remainder of the study, $8 \%$ sucrose was mixed in with the tastes. The reinforcers were $20 \%$ and $2 \%$ polycose.

Procedure. The training procedure was the same as in Experiment 3 , with the following exceptions. First, citric acid and quinine were the taste stimuli that were used (rather than salt and saccharin). Second, $8 \%$ sucrose was mixed in with the taste cues (rather than $2 \%$ sucrose). Third, two of the groups (Group PreExp-Taste and Group Pre-Exp-Ctl) were preexposed to the tastes mixed in $3.42 \%$ sucrose for 4 days and then to the tastes mixed in $8 \%$ sucrose. On half of the days, half of the animals in each group received citric acid, and the rest of the animals received quinine; on the other days, the animals received the other taste. This preexposure phase lasted 14 days. The two remaining groups (Group Taste and Group Control) received a tube of plain $8 \%$ sucrose during this phase. Finally, the taste cues were presented for $30 \mathrm{~min}$ rather than for $10 \mathrm{~min}$. Again, as noted earlier, the reason for this increase was that subjects did not drink appreciable amounts of the quinine solution.

The testing procedure remained the same, except that the test was for $30 \mathrm{~min}$ (the same as in training) and was between the taste cues mixed with $8 \%$ sucrose.

\section{Results}

Preexposure phase. On the two trials in which subjects were preexposed to quinine in $3.42 \%$ sucrose, they did not consume more than $2 \mathrm{ml}$. However, when the sucrose concentration was increased to $8 \%$, consumption increased dramatically. Group Pre-Exp-Taste and Group

Table 6

Mean Amount Consumed (in Milliliters) of Each Taste Cue in Testing in Experiment 3

\begin{tabular}{|c|c|c|c|c|}
\hline \multirow[b]{2}{*}{ Group } & \multicolumn{2}{|c|}{ Paired With $20 \%$ Polycose } & \multicolumn{2}{|c|}{ Paired With $2 \%$ Polycose } \\
\hline & Cue & Amt. & Cue & Amt. \\
\hline \multirow[t]{2}{*}{ Taste } & salt-sucrose & 20.33 & saccharin-sucrose & 1.54 \\
\hline & saccharin-sucrose & 18.00 & salt-sucrose & 1.42 \\
\hline \multirow[t]{2}{*}{ Control } & salt-sucrose & 11.21 & saccharin-sucrose & 11.96 \\
\hline & saccharin-sucrose & 12.33 & salt-sucrose & 8.17 \\
\hline
\end{tabular}

Note-In each row, the taste cues are given in the order of their presentation. Half the rats in each group received one presentation order; half received the other. 
Pre-Exp-Ctl-the groups that were preexposed to the taste cues-consumed a mean of $22.93 \mathrm{ml}$ of citric acid and of $18.25 \mathrm{ml}$ of quinine. The subjects drank significantly more of the citric acid cue than of the quinine cue $[F(1,22)=8.74, p<.01]$; they drank more over days $[F(4,19)=11.22, p<.001]$. The groups that were not preexposed to the taste cues (Group Taste and Group Control) consumed a mean of $24.25 \mathrm{ml}$ of plain $8 \%$ sucrose. Consumption did not vary by group $(F<1)$.

Training. All of the groups drank more of the taste cue that was paired with $20 \%$ polycose than they did of the taste cue that was paired with $2 \%$ polycose. There was no difference in consumption between the groups that were preexposed to the taste cues and the groups that were not.

An ANOVA for the taste cues included the same factors as in the previous experiments, with the addition of preexposure (preexposed vs. not preexposed) as a between factor. In training, all groups drank more of the taste cue that was paired with $20 \%$ polycose than they did of the taste cue that was paired with $2 \%$ polycose; this difference was significant $[F(1,16)=7.40, p<.02]$, although it was not significantly different between the groups $(F<1)$. Preexposure did not interact significantly with any other variable (largest $F<1$ ). The paired solution $\times$ counterbalancing interaction was significant $[F(1,16)=$ $92.08, p<.005]$. Table 7 shows the amount consumed of taste cues and reinforcers in training. Subjects in each of the groups drank more citric acid than quinine.

The main effect of reinforcer was not significant $(F<1)$; however, there was a group $\times$ reinforcer interaction $[F(1,16)=4.60, p<.05]$ because the experimental groups drank more of the $20 \%$ polycose solution, whereas the control groups did the reverse; these differences, however, were small. Counterbalancing had no effect in consumption of the reinforcers $[F(1,16)=4.27, p>.05]$.

Testing. Figure 4 shows the mean consumption of the taste cues in $8 \%$ sucrose for all four groups. All of the groups, regardless of preexposure to the taste cues, drank more of the cue paired with $20 \%$ polycose than they did of the one paired with $2 \%$ polycose.

An ANOVA included the same factors as in the previous experiments, with the addition of preexposure (preexposed vs. not preexposed) as a between factor. Prefer- ence for the cue paired with $20 \%$ polycose was significant $[F(1,16)=35.22, p<.005]$, as was the group $\times$ preference interaction $[F(1,16)=4.91, p<.05]$. The effect of preexposure was not significant $(F<1)$. Although the overall group $\times$ preference interaction was significant, none of the group $\times$ preference interactions were significant when pairs of groups were compared. NewmanKeuls tests $(p<.05)$ showed that Group Pre-Exp-Taste and Group Taste consumed significantly more of the taste paired with $20 \%$ polycose than they did of the taste paired with $2 \%$ polycose, whereas this difference was not significant for Group Pre-Exp-Ctl and Group Control. As can be seen in Table 8, preference was larger when the cue paired with $20 \%$ polycose was citric acid rather than quinine. Consistent with this, subsequent NewmanKeuls tests $(p<.05)$ showed that the preference for the cue paired with $20 \%$ polycose was significant for all groups and all subgroups, even when the cue paired with $20 \%$ polycose was quinine. The preference $\times$ counterbalancing interaction was significant $[F(1,16)=8.24$, $p<.02]$; however, the preference $\times$ counterbalancing $\times$ group interaction was not $[F(1,16)=2.57, p>.1]$.

\section{Discussion}

The results of Experiment 4 showed that a conditioned preference can be established using tastes that are inherently unpleasant. As in Experiment 3, we minimized the initial affective reaction to the tastes, although in this case the initial reaction was negative rather than positive. However, conditioning with these tastes (citric acid and quinine) required different procedures from those used with salt and saccharin. As noted earlier, we had to increase the training time from $10 \mathrm{~min}$ to $30 \mathrm{~min}$; because consumption of the quinine was negligible, the concentration of sucrose was increased from $3.42 \%$ to $8 \%$. Moreover, we did not reverse the preference for sour over bitter. Citric acid was still preferred over quinine, but this preference was reduced by the conditioning procedures. It may be that increasing the concentration of sucrose above $8 \%$ but to less than $20 \%$ will further reduce this preference or even reverse it. As mentioned earlier, in an unpublished experiment, a conditioned preference was not formed for any of the tastes (pleasant or unpleasant)

Table 7

Mean Amount Consumed (in Milliliters) of Each Taste Cue and Reinforcer in Training in Experiment 4

\begin{tabular}{|c|c|c|c|c|c|c|}
\hline \multirow[b]{3}{*}{ Group } & \multicolumn{3}{|c|}{ Paired With $20 \%$ Polycose } & \multicolumn{3}{|c|}{ Paired With 2\% Polycose } \\
\hline & & & Reinforcer & & & Reinforcer \\
\hline & Cue & Cue Amt. & Amt. & Cue & Cue Amt. & Amt. \\
\hline \multirow[t]{2}{*}{ Pre-Exp-Tst } & citric-sucrose & 22.90 & 8.30 & quinine-sucrose & 17.10 & 8.27 \\
\hline & quinine-sucrose & 17.00 & 9.60 & citric-sucrose & 20.10 & 6.83 \\
\hline \multirow[t]{2}{*}{ Pre-Exp-Ctl } & citric-sucrose & 21.13 & 21.83 & quinine-sucrose & 18.40 & 22.90 \\
\hline & quinine-sucrose & 19.20 & 21.10 & citric-sucrose & 20.57 & 22.23 \\
\hline \multirow[t]{2}{*}{ Taste } & citric-sucrose & 21.00 & 10.93 & quinine-sucrose & 12.10 & 14.10 \\
\hline & quinine-sucrose & 15.73 & 13.03 & citric-sucrose & 21.60 & 7.17 \\
\hline \multirow[t]{2}{*}{ Control } & citric-sucrose & 21.83 & 22.00 & quinine-sucrose & 14.67 & 24.70 \\
\hline & quinine-sucrose & 13.33 & 18.60 & citric-sucrose & 16.73 & 20.83 \\
\hline
\end{tabular}

Note-In each row, the taste cues are given in the order of their presentation. Half the rats in each group received one presentation order; half received the other. 


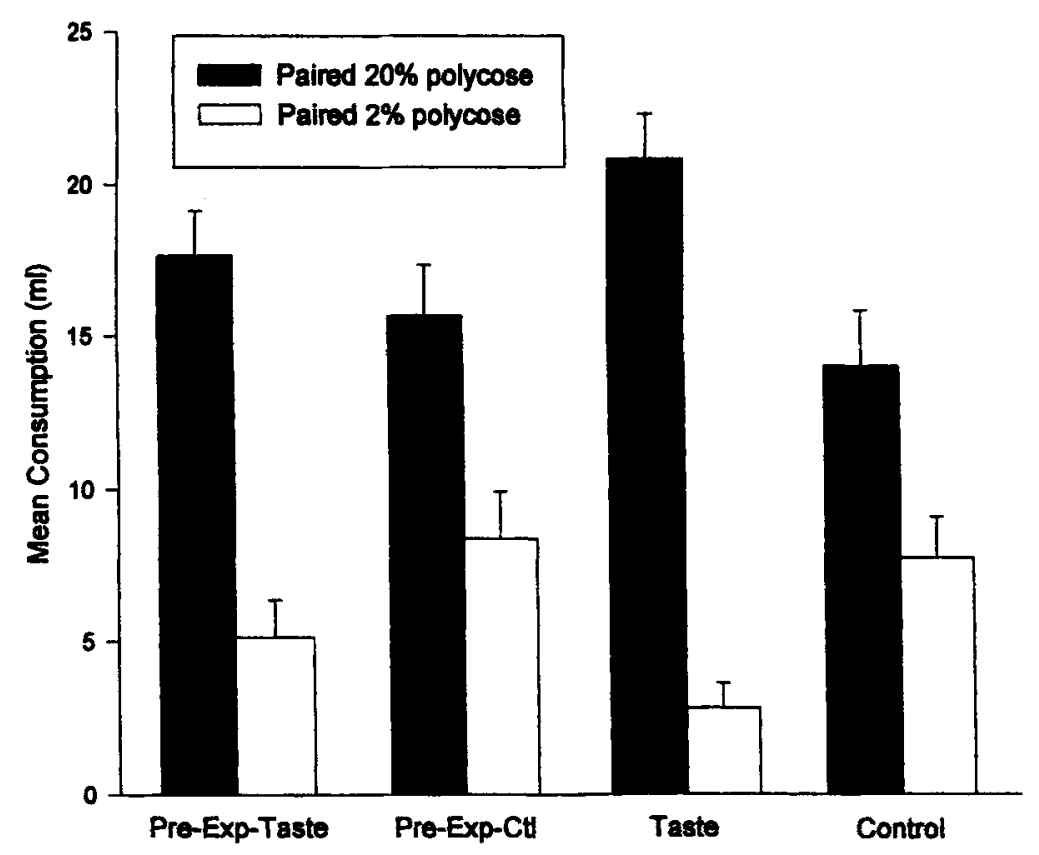

Figure 4. Mean milliliters consumed in test of the tastes (citric acid and quinine) that had been paired with $20 \%$ polycose or $2 \%$ polycose in training. In the test, the tastes were presented in $8 \%$ sucrose. Vertical lines represent standard error of the mean.

when they were mixed with $20 \%$ sucrose, probably because all solutions are highly liked when mixed with $20 \%$ sucrose. Thus, obtaining measurable conditioned preferences to tastes seems possible only if the tastes are not liked or disliked too much initially.

\section{GENERAL DISCUSSION}

The preceding experiments show that conditioning preferences to tastes is a much chancier affair than is conditioning with extracts (odors). The data from all four experiments are consistent with the notion that the US properties of tastes interfere with their functioning as CSs. Salt and saccharin are preferred to quinine and citric acid because of their inherent properties. Conditioned preferences were strong enough to overcome these inherent preferences in Experiment 2, when one cue was paired with $20 \%$ sucrose and the other with $.012 \%$ saccharin. These reinforcers differ in both calories and taste in training; they produced the largest difference in consumption of the reinforcers used in these experiments. Experiments 3 and 4 tested and confirmed the idea that, if the inherent difference in the reaction to the tastes could be minimized by mixing the tastes in with a common taste, a conditioned preference could be obtained. We do not know whether the difference between the tastes used here is qualitative or quantitative. What we do know is that the animals showed strong preferences between the tastes before conditioning, preferences that could be reversed or reduced by conditioning.

Experiment 2 showed that the tastes that failed to condition in Experiment 1 were strong enough to be discriminated; Experiments 1 and 2 showed that the reinforcers used in Experiment 1 were strong enough to produce a

Table 8

Mean Amount Consumed (in Milliliters)

of Each Taste Cue in Test in Experiment 4

\begin{tabular}{|c|c|c|c|c|}
\hline \multirow[b]{2}{*}{ Group } & \multicolumn{2}{|c|}{ Paired With $20 \%$ Polycose } & \multicolumn{2}{|c|}{ Paired With $2 \%$ Polycose } \\
\hline & Cue & Amt. & Cue & Amt. \\
\hline \multirow[t]{2}{*}{ Pre-Exp-Tst } & citric-sucrose & 20.67 & quinine-sucrose & 3.68 \\
\hline & quinine-sucrose & 14.67 & citric-sucrose & 6.58 \\
\hline \multirow[t]{2}{*}{ Pre-Exp-Ctl } & citric-sucrose & 21.00 & quinine-sucrose & 4.17 \\
\hline & quinine-sucrose & 10.33 & citric-sucrose & 2.58 \\
\hline \multirow[t]{2}{*}{ Taste } & citric-sucrose & 21.00 & quinine-sucrose & 2.67 \\
\hline & quinine-sucrose & 20.67 & citric-sucrose & 2.92 \\
\hline \multirow[t]{2}{*}{ Control } & citric-sucrose & 18.50 & quinine-sucrose & 4.58 \\
\hline & quinine--sucrose & 10.33 & citric-sucrose & 10.92 \\
\hline
\end{tabular}

Note-In each row, the taste cues are given in the order of their presentation. Half the rats in each group received one presentation order; half received the other. 
conditioned preference for extracts. Thus, it is the relationship between the reinforcers and the cues that is important. Conditioned preference experiments are best conducted using a two-bottle test (see Sclafani, 1972). Thus, in measuring a conditioned preference, one compares consumption of one substance with consumption of another. Rats almost always prefer one substance to another at the beginning of an experiment; this is compensated for by using counterbalancing, as we did here. When flavor extracts are used, there is often only a small initial preference, whereas with tastes there is a large initial preference. Thus, taste conditioning may be harder to demonstrate because of this larger initial difference.

This may not, however, be the critical difference between taste and odor conditioning. In some cases, the initial preference between flavor extracts can be quite large. In our lab, we found that rats generally have a strong dislike for peppermint (Capaldi \& Hunter, 1994). Nonetheless, we have obtained conditioned preferences for peppermint over the much preferred almond extract. Perhaps the reactions to taste are hard to overcome by preference conditioning because they are inherently liked or disliked.

Aversions are easily conditioned to tastes (Nowlis et al., 1980), perhaps because aversions are stronger than preferences, as was suggested by Rozin et al. (1979). Aversions also appear to be more easily conditioned to tastes than to odors (Hankins, Garcia, \& Rusiniak, 1973), which contrasts with our finding here that preferences are more easily conditioned to odors (extracts) than to tastes. Rusiniak et al. (1979) found that, in aversion conditioning, odors (extracts) are a weaker cue than tastes. However, in actuality there are very few studies that directly compare conditioning of tastes and odors in aversion conditioning (see Bouton, Jones, McPhillips, \& Swartzentruber, 1986; Bouton \& Whiting, 1982; Hankins et al., 1973), and there have been some reports of strong odor aversions (Bouton \& Whiting, 1982; Capaldi \& Lyn, 1997). Perhaps the apparent difference between aversion and preference conditioning is not a fundamental difference but a matter of procedural differences. Conditioned flavor preference experiments are customarily conducted under food deprivation, whereas conditioned taste aversion studies are customarily conducted under water deprivation. Perhaps odors are more easily conditioned under food deprivation than under water deprivation. We are currently conducting studies comparing preference and aversion conditioning under common procedures.

\section{REFERENCES}

Bartoshuk, L. M. (1991). Taste, smell and pleasure. In R. C. Bolles (Ed.), The hedonics of taste (pp. 15-28). Hillsdale, NJ: Erlbaum. Bouton, M. E., Jones, D. L., McPhillips, S. A., \& Swartzentruber, D. (1986). Potentiation and overshadowing in odor-aversion learning: Role of methods of odor presentation, the distal proximal cue dis- tinction, and the conditionability of odor. Learning \& Motivation, 17, 115-138.

Bouton, M. E., \& Whiting, M. R. (1982). Simultaneous odor-taste and taste-taste compounds in poison-avoidance learning. Learning \& Motivation, 13, 472-494.

Brackbill, R. M., Rosenbush, S. N., \& Brookshire, K. H. (1971). Acquisition and retention of conditioned taste aversions as a function of the taste quality of the CS. Learning \& Motivation, 2, 341-350.

CAPaldi, E. D., \& HUNTER, M. J. (1994). Taste and odor in conditioned flavor preference learning. Animal Learning \& Behavior, 22, 355-365.

CAPALDI, E. D., \& LyN, S. A. (1997). A comparison of conditioned flavor aversions and conditioned flavor preferences. Manuscript in preparation.

Doyle, T. G., Berridge, K. C., \& Gosnell, B. A. (1993). Morphine enhances hedonic taste palatability in rats. Pharmacology, Biochemistry \& Behavior, 46, 745-749.

Elizalde, G., \& SCLAFANI, A. (1990). Fat appetite in rats: Flavor preferences conditioned by nutritive and non-nutritive oil emulsions. Appetite, 15, 189-197.

FANSELOW, M. S., \& BirK, J. (1982). Flavor-flavor associations induce hedonic shifts in taste preference. Animal Learning \& Behavior, 10, 223-228.

FEDORCHAK, P. M., \& Bolles, R. C. (1987). Hunger enhances the expression of calorie- but not taste-mediated conditioned flavor preferences. Journal of Experimental Psychology Animal Behavior Processes, 13, 73-79.

Garcia, J. (1989). Food for Tolman: Cognition and cathexis in concert. In T. Archer \& L.-G. Nilsson (Eds.), Aversion, avoidance, and anxiety (pp. 45-85). Hillsdale, NJ: Erlbaum.

Hankins, W. G., Garcia, J., \& Rusiniak, K. W. (1973). Dissociation of odor and taste in baitshyness. Behavioral Biology, 8, 407-419.

HoLDER, M. D. (1991). Conditioned preferences for the taste and odor components of flavors: Blocking but not overshadowing. Appetite, $17,29-45$

LYNCH, W. C., \& LiBBY, L. (1983). Naloxone suppresses intake of highly preferred saccharin solutions in food deprived and sated rats. Life Sciences, 33, 1909-1914.

MoRrison, G. R., \& JessuP, A. (1977). Does saccharin have a dual taste for the rat? In J. M. Weiffenbach (Ed.), Taste and development. The genesis of sweet preference ( $\mathrm{pp} .42-47$ ). Washington, DC: U.S. Government Printing Office.

Nowlis, G. H., Frank, M. E., \& Pfaffmann, C. (1980). Specificity of acquired aversions to taste qualities in hamsters and rats. Journal of Comparative \& Physiological Psychology, 94, 932-942.

RozIN, P., Gruss, L., \& BERK, G. (1979). Reversal of innate aversions: Attempts to induce a preference for chili peppers in rats. Journal of Comparative \& Physiological Psychology, 93, 1001-1014.

Rusiniak, K. W., Hankins, W. G., Garcia, J., \& Brett, L. P. (1979). Flavor-illness aversions: Potentiation of odor by taste in rats. $B e-$ havioral \& Neural Biology, 25, 1-17.

ScLafani, A. (1972). The effects of food deprivation and palatability on the latency to eat of normal and hyperphagic rats. Physiology $\&$ Behavior, 8, 977-979.

Touzani, K., Akarid, K., \& Velley, L. (1991). Modulation of saccharin preferences by morphine and naloxone' Inversion of drug effects as a function of saccharin concentration. Pharmacology. Biochemistry \& Behavior, 38, 37-41.

Zellner, D. A., Berridge, K. C., Grill, H. J., \& Ternes, J. W. (1985). Rats learn to like the taste of morphine. Behavioral Neuroscience, 99, 290-300.

(Manuscript received June 21, 1996; revision accepted for publication May 6, 1997 ) 